\title{
Energy-Efficient Devices for Transporting and Feeding Bulk Materials in the Construction Industry
}

\author{
Alexander Ishkov ${ }^{1, *}$ \\ ${ }^{1}$ Moscow State University of Civil Engineering, 129337 Yaroslavskoye sh.26, Moscow, Russia
}

\begin{abstract}
Only in the construction industry millions of tons of bulk materials that need to be transported to the place of processing, storing and evenly or dosed feeding are recycled annually. Decreasing the costs of these processes will significantly reduce the cost of the finished product. The article presents a review of studies conducted in the field of storage, transport and feed bulk materials, and it describes the innovative design of energy-efficient disc vibrating feeder bulk materials.
\end{abstract}

\section{Introduction}

In the construction industry millions of tons of bulk materials that need to be transported to the place of processing, storing and evenly or dosed feeding are recycled annually. Thus, reducing the cost of transportation, storage and flow of granular materials significantly affects the cost of the finished product. Therefore, many researchers around the world are looking for ways to improve energy-efficiency of the above processes.

\section{Storage of Bulk Materials and Transportation in Special Conditions}

From review papers, you can highlight the article by A. W. Roberts [1], which presents a historical overview of the development of the processes of storage, transport and processing of bulk materials, as well as directions of future strategic studies.

In the field of storage of bulk materials the study of R. Selva Ganapathy and B. Pitchumani [2] can be identified. They studied the outflow of coal out of the bunker, depending form the bunker, angle of inclination of the walls and size of the outlet opening.

Bulk materials transportation is performed by various devices and in different conditions. Therefore, much research is devoted to studying these issues.

In the work of A. De Visscher [3] the article discusses environmental pneumatic unloading of wood pellets from barges to power plants in the Netherlands, and P. Mukhopadhyay and S. Chandrasekar [4] propose solutions aimed at improving the efficiency of loading coal on the trains in India. The system of loading and unloading bulk

* Corresponding author: aishkov@gmail.com 
materials from ships operating in the most severe weather conditions is presented in publication [5].

The Australian company Sea Transport Corporation and the Australian Maritime College at the University of Tasmania has developed new technology transshipment of bulk materials (iron ore and coal) from small feeder vessels to large bulk carriers [6], which gives a high environmental and economic effect, and in some cases completely eliminates to costly dredging operations. In this paper the issues of hydrodynamic interactions of multiple floating close to each other ships during the seaway is study.

J. Doller [7] describes the technology of pneumatic transport of bulk materials for the construction of a tunnel on the Swiss project NEAT.

Design, installation and operation the longest $(8.2 \mathrm{~km})$ in the world conveyor system in Peru is described in the article by J. Wiedenroth [8]. And in the work of S. Hoheisel [9] the commissioning of the longest in Europe belt conveyor for French cement factory in Montalieu is described. Its length is about $13 \mathrm{~km}$, and the total power of three motors is 750 $\mathrm{kW}$.

\section{Conveyor Systems Transport Bulk Materials}

The widespread use of conveyor systems pushes researchers to search for ways to improve their energy efficiency.

C. Wheeler, P. Munzenberger and D. Ausling [10] conducted a large studies to reduce the energy consumption of belt conveyors. Studies have helped to develop theoretical models that can be used in the design process of energy efficient systems of belt conveyors.

In publications [11] and [12] an energy-efficient samples of conveyor belts with lower rolling resistance to reduce energy consumption are proposed. And in the article by G. Lodewijks [13] discusses options of conveyor belts, made of new rubber compounds that can significantly reduce the consumed energy of the conveyor.

A wide range of produced rubber conveyor is presented in by R. Alles and K. Steinbrueck report about the Hannover Fair [14]. The authors mark trend toward standardization and automation of conveyors, as well as the wide use of plastics as loadbearing elements and protective coatings.

Studies conducted in recent years in the field of conveyor systems are mostly aimed at increasing the efficiency of transporting bulk materials. S. Ramjee and P. Staples [15] achieve this by improving the design of the conveyor. G. Lodewijks и Y. Pang [16] studied all possible energy-saving options for continuous transport systems. C. A. Wheeler [17] has developed a theoretical method of calculating the resistance to rotational motion of idler rolls in a conveyor belt system and a device to measure the strength of this resistance. G. $\mathrm{Hu}$ and colleagues [18] propose to use a discrete element method (DEM) to study the behavior of the equipment during transportation of powder and bulk materials.

\section{Systems Pneumatic Conveying of Bulk Materials}

Pneumatic conveyor systems of bulk material received are widespread in the industry. Therefore justified the attention, which researchers direct at increasing the energyefficiency of pneumatic transport installations.

Publication [19] describes the energy-efficient transporting system of cleaning products with compressed air, which helps in protecting the environment by reducing emissions. $\mathrm{N}$. Barlmeyer [20] proposes to transport the metal particles using negative pressure. C. Saccani, C. Panciroli and C. Ligabue [21] substantiate the advantages of pneumatic conveying installations for transporting granular particles and dust. 
T. Schuster, M. S. A. Bradley and A. R. Reed [22] investigated the impact properties of the bulk material, the diameter of pipelines and flow regime on the power consumption of pneumatic conveying systems.

In the work of S. Magister, J. Wildfoerster and P. Hilgraf [23] the results of studies of 10 pneumatic conveyor systems for transporting bulk materials at a lime plant are described. It helped to minimize the cost of electricity and compressed air.

L. Frye [24] developed a qualitative three-level model of the attrition process involving stress mode, aimed at determining the dominant mechanism of the abrasion in the process pneumatic transport of bulk materials.

\section{Transporting Bulk Materials by Means of Screw Device}

Screw conveyors have not lost their popularity.

M. Rackl and W. A. Günthner [25] conducted a pilot study of the effect of different varieties of wood chips on the performance of a screw conveyor. The results of the study allowed exclude jamming during transporting wood chips by a screw conveyor.

V. A. Evstratov, V. A. Rud and K. Y. Belousov [26] developed a mathematical model of the process of vertical screw transport of bulk material flow, this allows to reduce consumption energy of the conveyor, by means of the choice of optimal values of geometric, kinematic and dynamic parameters of working bodies.

\section{Systems Vibration Conveying of Bulk Materials}

Transportation of bulk and powder materials with the help of vibration is applied in many production processes in various industries, because it has a simple design, high reliability and efficiency.

Different designs of vibratory conveyors with electromagnetic drive are presented in the paper by R. Alles and K. Steinbrueck [27], devoted to the Hannover Fair. In the paper [28] K. Steinbrueck describes the benefits of vibration conveyors, in particular, the ability to solve many technological problems due to the change of the angle of inclination of the vibrating conveyor, the amplitude and frequency of its oscillation.

The work [29] is aimed at studying the impact of the transported material on heavyloaded vibrating conveyors and finding ways to prevent the occurrence of resonant frequency. The results of the study can be applied in the design of vibrating conveyors with electromagnetic drive.

The method of selection of vibratory conveyors depending on the kind of the bulk material and the operating conditions is presented in article [30]. S. Bhuvaneswari and S. Ravikumar [31] have developed a system of calculating the optimum power vibrating feeder, which allows to reduce energy consumption and increase equipment life.

\section{Vibratory Feed System Bulk Materials}

The quality of the finished product and the efficiency of many technological processes are often determined by the feeders - devices that provide a uniform flow of bulk materials to machines for their processing or transporting.

Vibration feeders [32] are widespread among the various types of feeders, since they have a simple design, small dimensions, have the reliability, accuracy and smoothness of control flow. Vibratory feeders bulk materials are used in the manufacture of building materials and other industries, for example, in the production of cement, building mixtures and etc. 
Disk vibratory feeder $[33,34]$ is widely used in the construction industry. It is placed coaxially underneath the exhaust pipe 1 of conical hopper 2 (Fig. 1). In the traditional embodiment the disk vibratory feeder is a horizontal spreading disk 3 , which is installed with a gap under the exhaust pipe 1 and connected with the electromagnetic drive 4 .

Feeder operates as follows.

Bulk material from the hopper 2 under the action of gravity poured through the exhaust pipe 1 on the spreading disc 3, where self-closes, forming on the disk 3 the annular mound with the natural angle of repose.

After switching the electromagnetic drive 4 the spreading disk 3 starts to vibrate. Bulk material, located on the spreading disk 3 , goes into a state of vibrating liquefaction. In this case the angle of repose of the granular material reduces and it begins to expire with spreading disk 3. After turning off the electromagnetic drive 4, the vibration spreading disk 3 is stopped and the bulk material self-closes, forming on the spreading disk 3 the sustainable annular mound with the natural angle of repose.

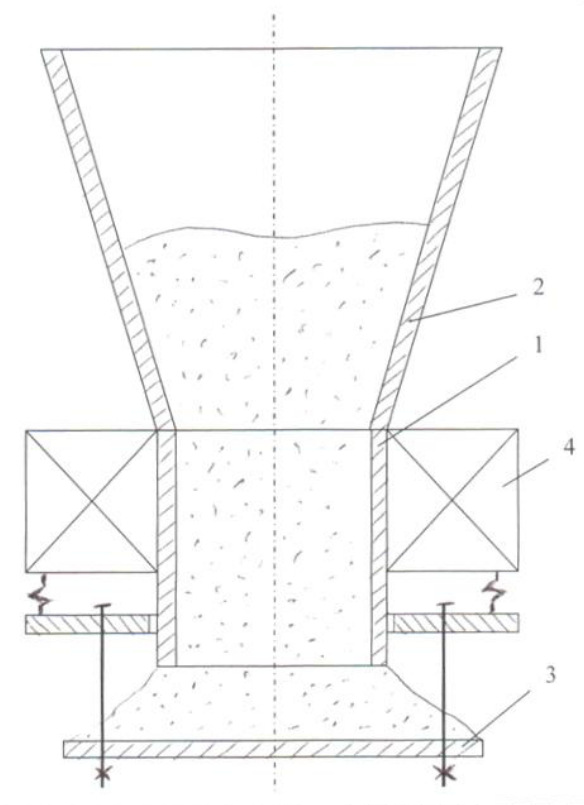

Fig. 1. Disc vibratory feeder of bulk materials.

\section{Results}

In the work [35] the energy-efficient design of the disc vibratory feeder is proposed. The spreading disc is formed with a central hole, overlapped with elastic membrane. The researchers were able to reduce specific energy consumption per unit of supplied granular material due to a sharp (5-6 times) increase in performance of the feeder. According to the authors, this effect is due to increased driving force of the expiry of the material (pressure of the column of material in the hopper) and the increase of the oscillation amplitude of the spreading disk due to the elastic properties of the membrane.

In the future the design of energy-efficient disc vibratory feeder of bulk materials was improved (Fig. 2). The elastic membrane, overlapping the central hole in the spreading disk 3 is removed, and under the spreading disk 3 is mounted with a gap coaxially fixed disk 5 , rigidly secured to the hopper 2 . 
The advanced design of the energy-efficient disc vibratory feeder allows you to eliminate wasteful expenditure of electricity on useless vibration of the central part of the pillar of bulk material, located in the hopper 2 .

\section{Conclusion}

The advanced design of the energy-efficient disc vibratory feeder reduces the cost of electricity for $16-27 \%$. Research in this direction continues, but the disc vibratory feeder is already in use at the enterprises of the construction industry.

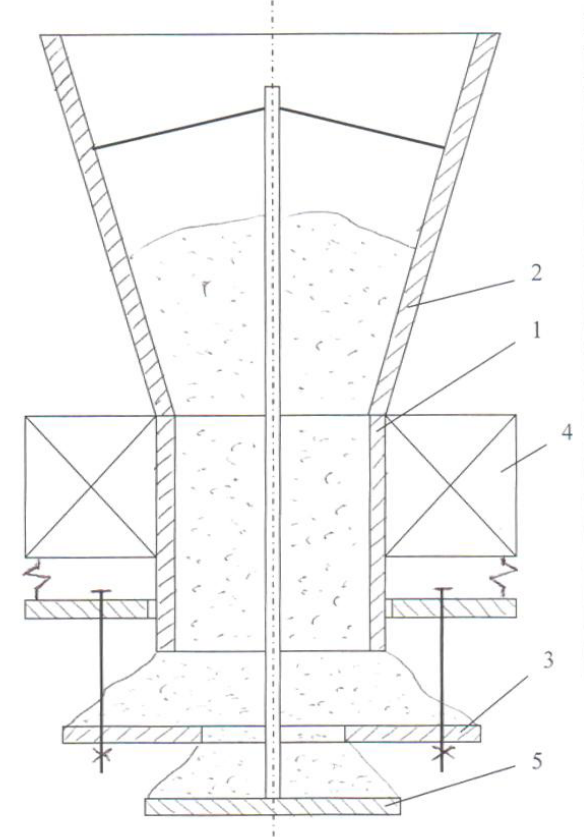

Fig. 2. Advanced disc vibratory feeder of bulk materials.

\section{References}

1. A.W. Roberts, Bulk Solids Handling, 26-6, 392-414 (2006)

2. R. Selva Ganapathy, B. Pitchumani, Bulk Solids Handling, 29-4, 218-222 (2009)

3. A. De Visscher, Bulk Solids Handling, 33-4, 32-33 (2013)

4. P. Mukhopadhyay, S. Chandrasekar, Bulk Solids Handling, 35-5, 30-32 (2015)

5. Bulk handling in extreme conditions (2007)

6. G.J. Macfarlane, N.T.M. Johnson, L.J. Clarke, R.J. Ballantyne, K.A. McTaggart, , Proceedings of the International Conference on Offshore Mechanics and Arctic Engineering - OMAE, 7, (2015).

7. J. Doller, ZKG International, 58-6, 67-71 (2005)

8. J. Wiedenroth, Cement International, 7-4, 54-63 (2009)

9. S. Hoheisel, Bulk Solids Handling, 35-1, 17-19 (2015)

10. C. Wheeler, P. Munzenberger, D. Ausling, Bulk Solids Handling, 35-5, 40-50 (2015)

11. M. Hager, A. Hintz, Bulk Solids Handling, 13, 749-758 (1993)

12. A. Greune, M. Hager, Bulk Solids Handling, 10, 245-248 (1990)

13. G. Lodewijks, Bulk Solids Handling, 32, 52-56 (2012) 
14. R. Alles, K. Steinbrueck, Foerdern Heben, 21-10, 571-581 (1971)

15. S. Ramjee, P. Staples, Bulk Solids Handling, 35- 4, 20-25 (2015)

16. G. Lodewijks, Y. Pang, Energy saving options for continuous transport systems, an exploration, ICBMH 2013 - 11th International Conference on Bulk Materials Storage, Handling and Transportation (Newcastle, NSW; Australia, 2013)

17. C.A. Wheeler, Journal of Manufacturing Science and Engineering, Transactions of the ASME, 138-4, (2016)

18. G. Hu, M. Liu, Y. Liu, H. Wan, L. Liu, 2010 International Conference on Mechanic Automation and Control Engineering, MACE2010, 923-926 (2010)

19. Powder Handling and Processing, 18-1, 44-46 (2006)

20. N. Barlmeyer, Bulk Solids Handling, 33-1, 28-30 (2013)

21. C. Saccani, C. Panciroli, C. Ligabue, Powder Handling and Processing, 13-3, 295-299 (2001)

22. T. Schuster, M.S.A. Bradley, A.R. Reed, Proceedings of the Institution of Mechanical Engineers, Part E: Journal of Process Mechanical Engineering, 209-E1, 69-75 (1995)

23. S. Magister, J. Wildfoerster, P. Hilgraf, ZKG international, 41-12, 601-606 (1988)

24. L. Frye, Handbook of Powder Technology, 12, 1149-1218 (2007)

25. M. Rackl, W.A. Günthner, Biomass and Bioenerg, 88, 106-115, (2016)

26. V.A. Evstratov, A.V. Rud, K.Y. Belousov, Procedia Engineering, 129, 397-402 (2015)

27. R. Alles, K. Steinbrueck, Foerdern Heben, 21-10, 582-589 (1971)

28. K. Steinbrueck, AEG-Telefunken Progress, 4, 102-107 (1981)

29. K. Steinbrueck, Aufbereitungs-Technik, 22-8, 410-417 (1981)

30. K. Steinbrueck, Technische Mitteilungen AEG-Telefunken, 71-3, 87-93 (1981)

31. S. Bhuvaneswari, S. Ravikumar, International Journal of Applied Engineering Research, 10-7, 16441-16449 (2015)

32. A.D. Ishkov, D.A. Semernin, S.V. Miloradov, I.V. Voronina, Applied Mechanics and Materials, 741, 500-503 (2015)

33. G.G. Arsoev, R.U. Patent 2,340,530. (2008).

34. A.D. Ishkov, A.V. Kosjakov, A.N. Cetovich, F.M. Filipkov and O.Ju.Grigor'ev, S.U. Patent 1,590,414 (1990)

35. A.D. Ishkov, A.V. Stepanov, S.V. Miloradov, I.V. Voronina, Applied Mechanics and Materials, 670-671, 458-461 (2014) 